\title{
Application of Fragrance Microcapsules onto Cotton Fabric after Treatment with Oxygen and Nitrogen Plasma
}

\author{
Mateja Kert ${ }^{1}$, Petra Forte Tavčer ${ }^{1}$, Aleš Hladnik ${ }^{1} \mathbb{D}$, Kosta Spasić ${ }^{2}$, Nevena Puač ${ }^{2} \mathbb{D}, Z$ Zoran Lj. Petrović ${ }^{3,4}$ \\ and Marija Gorjanc 1,*(D)
}

1 Faculty of Natural Sciences and Engineering, University of Ljubljana, Aškerčeva 12, SI-1000 Ljubljana, Slovenia; mateja.kert@ntf.uni-lj.si (M.K.); petra.forte@ntf.uni-lj.si (P.F.T.); ales.hladnik@ntf.uni-lj.si (A.H.)

2 Institute of Physics of Belgrade, University of Belgrade, Pregrevica 118, 11080 Belgrade, Serbia; kosta.spasic@ipb.ac.rs (K.S.); nevena@ipb.ac.rs (N.P.)

3 Serbian Academy of Sciences and Arts, Knez Mihajlova 35, 11000 Belgrade, Serbia; zoran@ipb.ac.rs or z.petrovic@ulster.ac.uk

4 Nanotechnology and Integrated Bio-Engineering Centre (NIBEC), School of Engineering, University of Ulster, Newtownabbey, Antrim BT37 0QB, UK

* Correspondence: marija.gorjanc@ntf.uni-lj.si

Citation: Kert, M.; Forte Tavčer, P.; Hladnik, A.; Spasić, K.; Puač, N.; Petrović, Z.L.; Gorjanc, M. Application of Fragrance Microcapsules onto Cotton Fabric after Treatment with Oxygen and Nitrogen Plasma. Coatings 2021, 11, 1181. https://doi.org/ 10.3390/coatings11101181

Academic Editor: Fabien Salaün

Received: 25 August 2021

Accepted: 24 September 2021

Published: 28 September 2021

Publisher's Note: MDPI stays neutral with regard to jurisdictional claims in published maps and institutional affiliations.

Copyright: (c) 2021 by the authors. Licensee MDPI, Basel, Switzerland. This article is an open access article distributed under the terms and conditions of the Creative Commons Attribution (CC BY) license (https:// creativecommons.org/licenses/by/ $4.0 /)$.

\begin{abstract}
Cotton fabric was exposed to low-pressure capacitively coupled plasma to enhance the adsorption and adhesion of fragrance microcapsules (FCM). Two plasma-forming gases, namely oxygen $\left(\mathrm{O}_{2}\right)$ and nitrogen $\left(\mathrm{N}_{2}\right)$, were investigated. The untreated and plasma-treated samples were investigated for their morphological changes by scanning electron microscopy (SEM), mechanical properties (breaking force, elongation, and flexural rigidity), and wicking properties. The cotton samples were functionalized with FCM and the effect of plasma pretreatment on the adsorption and adhesion of FCM was evaluated using SEM, air permeability, fragrance intensity of unwashed and washed cotton fabrics, and Fourier transform infrared spectroscopy (FTIR). The results show that the plasma containing either of the two gases increased the wicking of the cotton fabric and that the $\mathrm{O}_{2}$ plasma caused a slight etching of the fibers, which increased the tensile strength of the cotton fabric. Both plasma gases caused changes that allowed higher adsorption of FCM. However, the adhesion of FCM was higher on the cotton treated with $\mathrm{N}_{2}$ plasma, as evidenced by a strong fragrance of the functionalized fabric after repeated washing.
\end{abstract}

Keywords: fragrance microcapsules; cotton; oxygen plasma; nitrogen plasma

\section{Introduction}

Textiles with embedded fragrance microcapsules are a class of cosmetotextiles and are called aromatherapeutic textiles [1]. Such textiles provide the scent of essential oils derived from plant-based raw materials, which could boost the emotional and physical scene of the body [2]. Fragrance microcapsules consist of essential oils or fragrant compounds in the core and polymers as a wall material. The controlled release of the essential oil from the polymer layer of the microcapsule relies on four mechanisms: mechanical stimuli (during the application of mechanical force in processing), chemical stimuli (the core material slowly dissolves in the shell membrane), thermal stimuli (heat), and diffusion [3]. Cotton is a textile material found in many practical applications, such as fibrous porous media, clothing, household, and health care textiles and could be a promising textile substrate for application of fragrance microcapsules for aromatherapeutic textiles [1-4]. The embedding of fragrant microcapsules on textiles imparts new properties and added value to products, with multiple applications such as clothing, decorative textiles, and non-implantable medical textiles [5]. Application of microcapsules to textiles can be done by padding, coating, immersion, spraying, and printing [6-10]. The results of research reports comparing different methods of applying fragrant microcapsules to textiles (i.e., printing, padding, 
exhaustion) show that the padding technique is more suitable than others because the yield is higher, fewer chemicals are required, and it can be done at room temperature $[6,9,10]$. A major problem associated with the application of microcapsules on textiles is the loss of textile functionality after a few wash cycles, even if binders are used in the application. Factors that influence the increase in wash resistance are the use of acrylic binders, proper curing conditions, and plasma pretreatment [11-19]. The advantage of plasma pretreatment is that it is a dry process that enables an introduction of functional groups on fibers and polymers in an environmentally friendly manner. During plasma treatment, the surface morphology of the treated samples is changed without affecting their bulk properties. Combination of changed morphology and activated surface allows increased embedment of nanoparticles, microcapsules, dyes, and other coatings [20-25]. The plasma used for the functionalization of textile surfaces has to be non-equilibrium, which means that electrons have to have few orders of magnitude higher temperature than ions or neutral species. In these kind of discharges, heavy particles (ions and neutrals) usually have energies that correspond to room temperature. Additionally, plasma needs to produce ample radicals and other active species that would open bonds on the substrate surface and make it possible to produce binding sites for the microcapsules. All these requirements can be accomplished by using a low-pressure plasma that would properly activate the surface, but it would also make it possible to treat materials that may be strongly affected or even destroyed by high temperatures [26-34]. Previously published research on improving the adsorption or adhesion of microcapsules using plasma has mainly focused on atmospheric dielectric barrier discharge (DBD) air plasma on cotton/polyester, wool and natural cork $[13,15,18]$, atmospheric air corona plasma on bamboo [16], and low-pressure oxygen plasma on polydimethylsiloxane [17]. The improved adsorption of crosslinkers and phase change materials on plasma-treated materials was attributed to the increased wettability and surface energy, either due to the higher plasma dosage (in $\mathrm{W} \cdot \mathrm{min} / \mathrm{m}^{2}$ ) or the power of the plasma reactor (in $\mathrm{W}$ ). No attempts have been made to investigate different gases for the generation of plasma discharge, except in our previously published work, where polyethylene terephthalate was modified with oxygen and ammonia plasma to improve the embedding of UV-responsive microcapsules [32].

Since the important factor in plasma pretreatment for improved embedding of coatings is also related to the proper choice of working gas, in this study, we focused on the treatment of cotton fabric with oxygen and nitrogen plasma discharges to evaluate which gas is more suitable for functionalizing cotton fabric and enhancing the binding of fragrance microcapsules.

\section{Materials and Methods}

\subsection{Materials}

A chemically bleached $100 \%$ cotton fabric from the manufacturer Tekstina d.d., Ajdovščina, Slovenia, was used for the study (plain weave, mass $125 \mathrm{~g} / \mathrm{m}^{2}$, warp density 50 threads/cm, weft density 30 threads $/ \mathrm{cm}$ ). Suspension of $2-8 \mu \mathrm{m}$ sized microcapsules with a pressure-sensitive melamine-formaldehyde wall and a liquid core were prepared at Aero d.d., Celje, Slovenia, by in situ polymerization of melamine-formaldehyde prepolymers [35]. The mass fraction of cores in all microcapsules was $75 \%$ and the mass fraction of walls was $25 \%$. The mass fraction of microcapsules in suspensions was $32 \%$. The core of the microcapsules contained strawberry essential oil in isopropyl myristate as solvent $(25 \%$ essential oil and $75 \%$ isopropyl myristate). Thermal and mechanical properties of these microcapsules are reported in the literature [36,37]. The binder used was acrylic (Itobinder AG, MagnaColours, Barnsley, UK).

\subsection{Treatment of Cotton in Plasma}

The treatments of cotton samples were carried out in a Capacitively Coupled Plasma (CCP) system [38,39], which is shown in Figure 1. The discharge chamber is made of stainless steel and is cylindrical in shape $(46 \mathrm{~cm}$ long with diameter of $37 \mathrm{~cm})$. The powered 
electrode is an axially placed aluminum rod (diameter $14 \mathrm{~mm}$ ), while the chamber walls serve as the grounded electrode. The sample holder is located at the bottom of the chamber and is also electrically grounded. Power is supplied by a commercially available power supply unit Dressler Cesar 1310 (Advanced Energy, Campbell, CA, USA) at $13.56 \mathrm{MHz}$ in combination with an automatic matching network Variomatch (Advanced Energy, Campbell, CA, USA). This device allows precise control and tuning of both transmitted and reflected power. Treatments were performed at $100 \mathrm{~W}$, while the reflected power was maintained at 0 W. A mechanical pump (DUO 65, Pfeiffer Vacuum GmbH, Asslar, Germany) was used to generate the vacuum, while pressure control was achieved by regulating the influx gasses with a mass flow controller. Namely, we used the two working gases oxygen $\left(\mathrm{O}_{2}\right)$ and nitrogen $\left(\mathrm{N}_{2}\right)$ at a constant pressure of $200 \mathrm{mTorr}$. To keep this pressure constant, the flow of oxygen (for $\mathrm{O}_{2}$ plasma) and nitrogen (for $\mathrm{N}_{2}$ plasma) was $85 \mathrm{sccm}$. The treatment time for all samples was $5 \mathrm{~min}$.

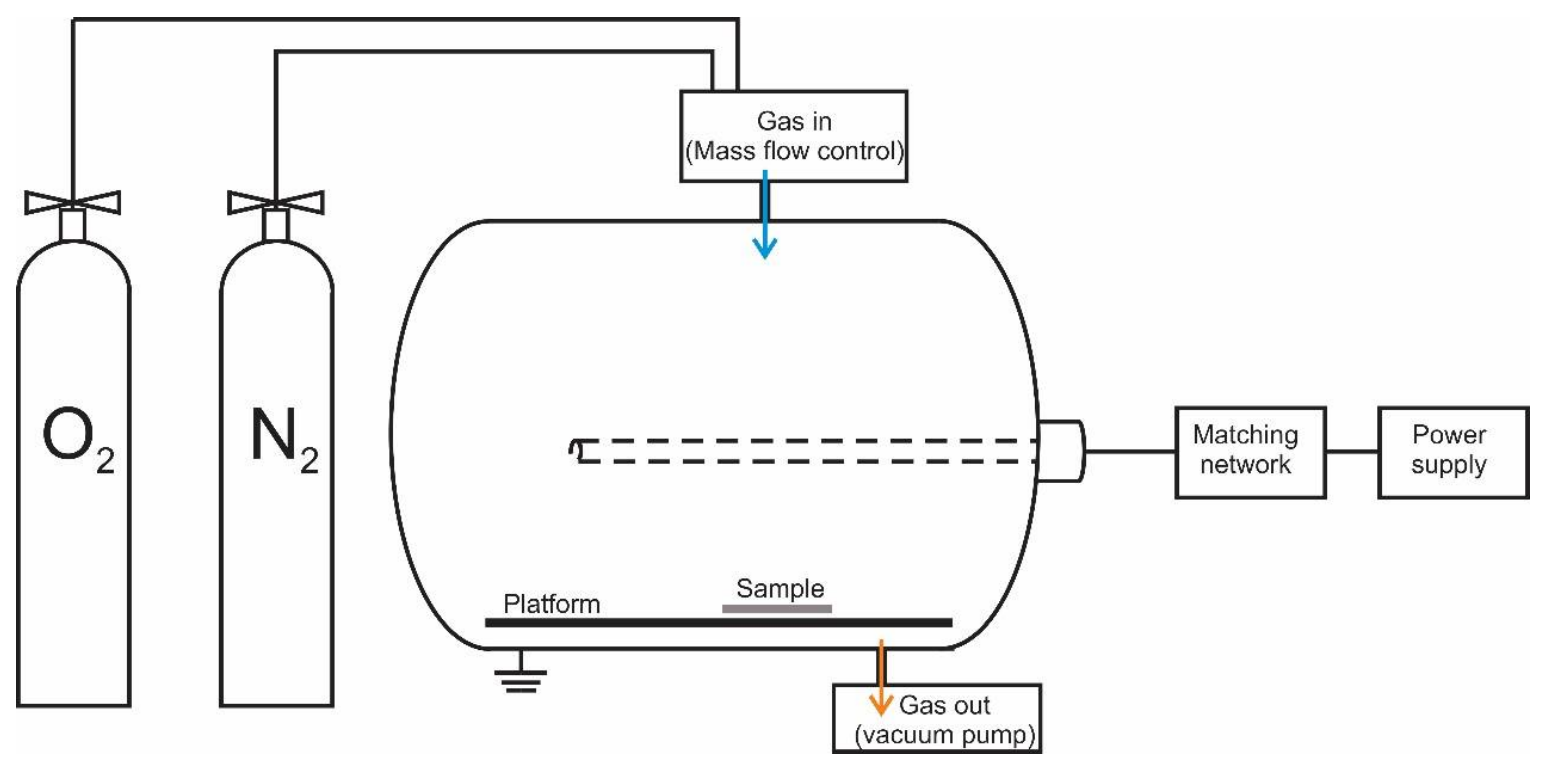

Figure 1. Asymmetrical CCP system used for treatments of cotton samples. The power of the RF power supply was $100 \mathrm{~W}$, the working gases were $\mathrm{O}_{2}$ and $\mathrm{N}_{2}$, the pressure $200 \mathrm{mTorr}$ and the treatment time $5 \mathrm{~min}$. The platform positioned at the bottom of the chamber is grounded.

\subsection{Application of Microcapsules}

The untreated and plasma treated cotton fabrics were coated with fragrance microcapsules using the pad-dry-cure method. The cotton fabrics were padded with prepared padding bath containing $50 \mathrm{~g} / \mathrm{L}$ microcapsule suspension and $50 \mathrm{~g} / \mathrm{L}$ Itobinder AG (MagnaColours, Barnsley, UK) at room temperature using $80 \%$ wet pick up. After padding, the fabrics were dried at $100{ }^{\circ} \mathrm{C}$ for $3 \mathrm{~min}$ and cured at $150{ }^{\circ} \mathrm{C}$ for $5 \mathrm{~min}$.

\subsection{Scanning Electron Microscopy}

The morphology of the cotton fabrics was recorded using a scanning electron microscope (SEM; JEOL SEM type JSM-6060LV, Jeol, Tokyo, Japan) [32]. Before scanning, all samples were coated with a thin layer of gold. The electron beam voltage used was $10 \mathrm{kV}$, the electric current was $85 \mu \mathrm{A}$ and the spot size (diameter of the electron probe) was 30 .

\subsection{Tensile Property of the Fabrics}

The breaking force, expressed in N (newton), and the elongation, expressed in \%, of the untreated and the plasma treated fabrics was analyzed according to the standard SIST EN ISO 13934-1:2013 [40] using an Instron 6022 dynamometer (Instron, Norwood, MA, USA) [41]. The $150 \mathrm{~mm} \times 20 \mathrm{~mm}$ samples were analyzed in the warp direction with a 
preload of $1 \mathrm{~N}$ and a speed of $100 \mathrm{~mm} / \mathrm{min}$. Ten samples were analyzed for each treatment and the average value and standard deviation were calculated.

\subsection{Fabrics Stiffness}

The stiffness of the untreated and plasma-treated fabric was evaluated as a flexural rigidity according to the standard ASTM D1388-Option A: Cantilever Test [42], employing the principle of cantilever bending of the fabric under its own mass [43]. Twelve test specimens of each treatment were cut to size $150 \mathrm{~mm} \times 25 \mathrm{~mm}$ (longer side in warp direction) and placed on a smooth, low-friction horizontal platform inclined at $41.5^{\circ}$. A weighted sled was placed over the specimen and moved forward at a constant speed. When the specimen bent and touched the slope of the platform, the length of the overhang was measured in centimeters. Flexural rigidity $(G)$ was calculated from Equation (1):

$$
G=W \times\left(\frac{O}{2}\right)^{3}
$$

where $W$ is mass per unit area $\left(\mathrm{mg} / \mathrm{cm}^{2}\right), O$ is the length of overhang $(\mathrm{cm})$.

The average and standard deviation of twelve measurements for each treatment were calculated.

\subsection{Absorptiveness of Fabrics}

The untreated and plasma-treated cotton fabrics were tested for their absorbency using the capillary rise method according to the standard DIN 53924 [44]. Four samples of size of $250 \mathrm{~mm} \times 30 \mathrm{~mm}$ were prepared. Each sample was hung vertically and aligned parallel to the ruler with millimeter divisions. The lower end of the sample was immersed $10 \mathrm{~mm}$ deep into the lightly colored distilled water. After 30, 60, and $300 \mathrm{~s}$, the height of the wicking above the water surface was measured. The results are given as the mean and standard deviation of the four measurements.

\subsection{Fragrance Evaluation}

The method for fragrance evaluation was based on the Lewis procedure [10-12] with a panel of thirty judges. The samples were first hung on a clothesline in a room for $1 \mathrm{~h}$ to stabilize the evaporation of the fragrance. Then the samples were taken to a judge in an evaluation room. The cotton fabric coated with microcapsules was placed on a flat, hard plate on a table. The judges used their fingernails to scratch an " $\mathrm{X}$ " into the fabric to break some of the microcapsules and smell the sample. They then noted a "yes" for the presence of a strong, medium, or weak scent or a "no" for the absence of any scent. No judge tested for more than $15 \mathrm{~min}$. If a scent was judged to be present by a majority of the judges, the condition was recorded as "passed." Judges were required to evaluate samples from three treatments: untreated, $\mathrm{O}_{2}$ and $\mathrm{N}_{2}$ plasma treated samples coated with fragrance microcapsules, before and after repeated washing. Results are presented as the number of responses from judges who scored each treatment.

\subsection{Air Permeability of the Fabrics}

The air permeability of cotton samples coated with microcapsules before and after repeated washing cycles was determined according to the standard SIST EN ISO 9237:1999 [45] using the AirTronic 3240B air permeability tester (Mesdan, Raffa, Italy) at a pressure drop of $1000 \mathrm{~Pa}$. The air permeability, expressed in $\mathrm{mm} / \mathrm{s}$, was calculated according to the following Equation (2):

$$
R=\frac{q_{v}}{A} \times 167
$$

where $q_{v}$ is the arithmetic mean of the air flow rate in $\mathrm{L} / \mathrm{min}, A$ is the area of the fabric tested in $\mathrm{cm}^{2}$, and 167 is the conversion factor from $\mathrm{L} / \mathrm{min}$ to $\mathrm{mm} / \mathrm{s}$.

The results are given as the mean and standard deviation of the four measurements. 


\subsection{Fastness of the Coated Fabric to Washing}

Washing of microcapsule-coated cotton fabrics was performed in laboratory washing apparatus Launder-Ometer (SDL Atlas, Rock Hill, SC, USA), using $4 \mathrm{~g} / \mathrm{L}$ of standard detergent European Colorfastness Establishment (ECE) for $45 \mathrm{~min}$ at $40^{\circ} \mathrm{C}$ according to the standard SIST EN ISO 105-C06:2012 [46]. The number of washing cycles was 1, 5, and 10. To simulate five domestic washings, 10 stainless steel balls were added to each wash bath. After washing, the samples were rinsed twice with distilled water and then air dried at room temperature.

\subsection{Fourier-Transform Infrared Spectroscopy (FTIR)}

The ATR-FTIR (attenuated total reflectance-Fourier transform infrared spectroscopy) spectra of the untreated and plasma treated samples were recorded using an FTIR spectrophotometer (Bruker IFS 66/S, Billerica, MA, USA). The spectra were recorded from samples pressed firmly against a cylindrical Ge crystal. The resolution of the instrument was $4 \mathrm{~cm}^{-1}$ for 64 scans and the spectra were obtained over the range $4000-600 \mathrm{~cm}^{-1}$. To better interpret the spectra, a principal component analysis (PCA) was performed on the data obtained. PCA [47] is a commonly used chemometric technique [48,49] that linearly and orthogonally transforms the original data into a new coordinate system of principal components (PCs). The number of extracted PCs is equal to the number of original variables, but in general the first few-two or three-PCs are already responsible for most of the variability in the data. Their visualization allows to detect hidden patterns and trends in the data. PCA was performed after baseline correction of each spectrum run using MATLAB $^{\circledR}$ (ver 2014b, MathWorks, Inc., Natick, MA, USA).

\section{Results and Discussion}

Increasing the adsorption and adhesion of microcapsules on cotton fabric enables wash durability of the coating and thus the development of the value-added textile products. To achieve this, the use of environmentally friendly technologies, such as plasma treatment, plays a crucial role. Cotton fabrics were treated with oxygen $\left(\mathrm{O}_{2}\right)$ and nitrogen $\left(\mathrm{N}_{2}\right)$ in capacitively coupled plasma to evaluate which working gas is more suitable for modifying cotton to achieve increased uptake (adsorption) of the fragrance microcapsules and ensure good adhesion to the fibers. Firstly, the properties of the untreated and plasmatreated fabrics without microcapsules were evaluated to analyze their surface morphology, breaking strength and elongation, flexural rigidity, and wicking. The surface morphology of the fibers changes only after treating the fabric with $\mathrm{O}_{2}$ (Figure $2 b$ ), but not after treating the fabric with $\mathrm{N}_{2}$ plasma (Figure 2c). The $\mathrm{O}_{2}$ plasma-treated sample (Figure 2b) exhibits visible cellulose fibrils extending out of the fiber surface, similar to those observed after treatment with inductively coupled water vapor plasma [22] and air corona plasma [50]. The reason of changed topography is the etching effect of $\mathrm{O}_{2}$ plasma treatment. In oxygenrich plasma, the reactive species cause chemical erosion (atoms) and physical erosion (ions) [51,52]. Flynn et al. [51] and Vesel et al. [52] also reported that nitrogen-rich plasma (i.e., nitrogen or ammonia gases) does not have a significant effect on surface roughness due to the difference in etch rate compared to oxygen-rich plasma (i.e., water vapor, air, or oxygen gases), but it does on the surface functionalization with nitrogen-rich groups. Similar results were found by Pranslip et al. [53] who treated cotton fabric with oxygen, nitrogen, and hexafluoride $\left(\mathrm{SF}_{6}\right)$ plasma to improve ink absorption. While $\mathrm{O}_{2}$ and $\mathrm{SF}_{6}$ plasma provided a stronger impulse to increase surface roughness, the $\mathrm{N}_{2}$ plasma had only a very weak etching effect even after 20 min of plasma treatment. 


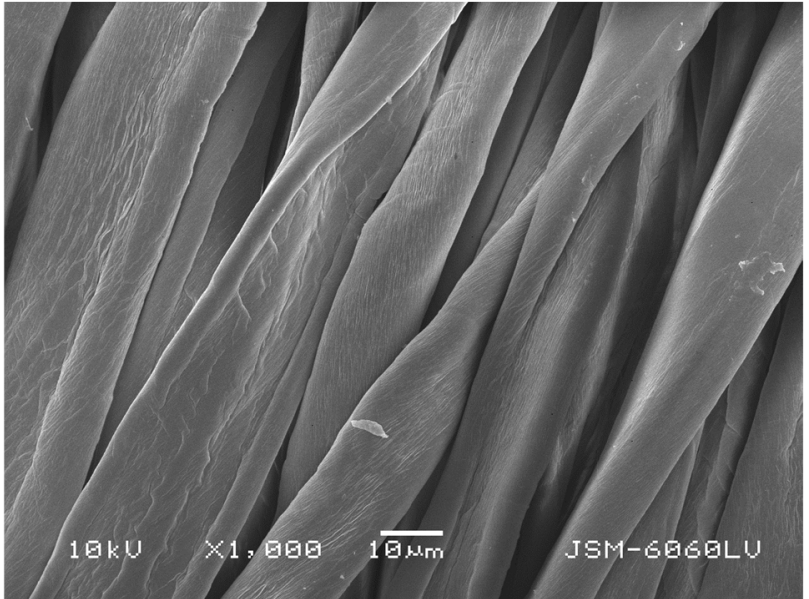

(a)

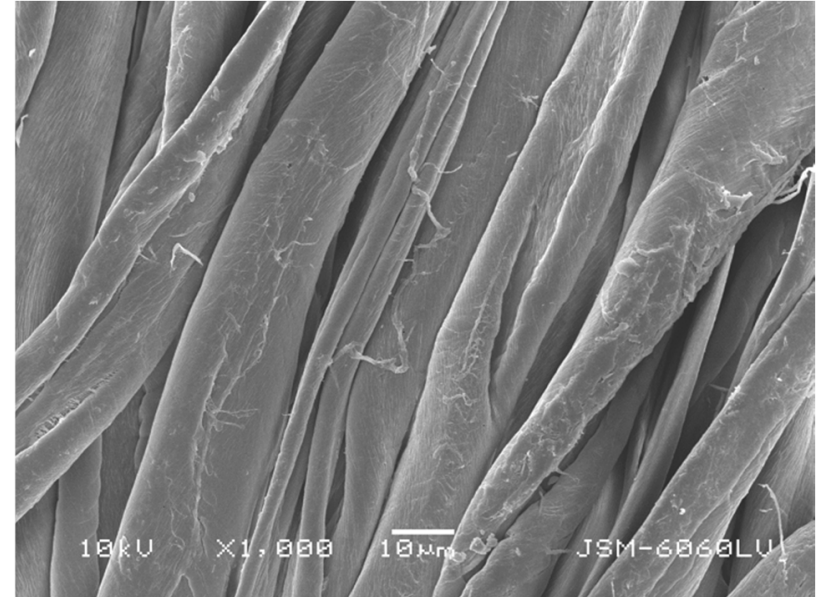

(b)

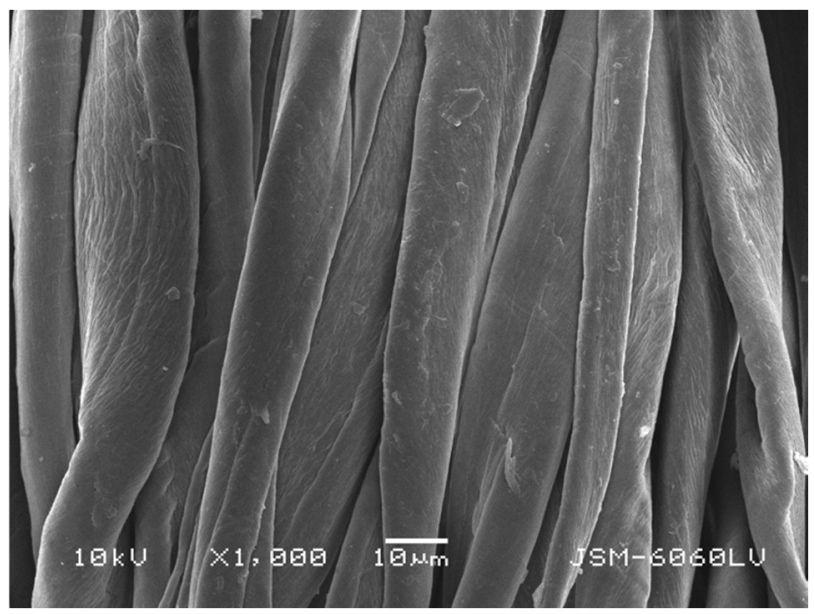

(c)

Figure 2. SEM images of (a) untreated, (b) $\mathrm{O}_{2}$ plasma-treated, and (c) $\mathrm{N}_{2}$ plasma-treated samples of cotton fabric.

The morphological changes caused by etching the surface of the cotton fibers could lead to a deterioration of the mechanical properties of the fabrics. However, the results presented in Table 1 show that breaking strength of the cotton fabric increases after plasma treatment, whilst the breaking elongation also increases but to a much lesser extent. The effect is more pronounced for the samples treated with $\mathrm{O}_{2}$ plasma. An interesting effect observed on plasma-treated fabrics was lower flexural rigidity, i.e., the fabrics were less stiff after plasma treatment. The explanation for such an effect could be weight loss due to the etching effect of plasma [53]. However, in our case, the etching effect of $\mathrm{O}_{2}$ plasma was low (Figure $2 \mathrm{~b}$ ), and no etching effect was observed on the sample treated with $\mathrm{N}_{2}$ plasma (Figure 2c), which had the lowest value for flexural rigidity.

Table 1. Breaking strength $(\mathrm{N})$ and elongation $(\mathrm{mm})$ and flexural rigidity $(\mathrm{mg} \cdot \mathrm{cm})$ of untreated and plasma-treated samples.

\begin{tabular}{cccc}
\hline Sample & $\begin{array}{c}\text { Breaking Force } \\
\mathbf{( N )}\end{array}$ & $\begin{array}{c}\text { Breaking Elongation } \\
\mathbf{( \% )}\end{array}$ & $\begin{array}{c}\text { Flexural Rigidity } \\
\mathbf{( m g \cdot c m})\end{array}$ \\
\hline Untreated & $357.7 \pm 13.0$ & $14.9 \pm 1.4$ & $266.0 \pm 18.6$ \\
\hline $\mathrm{O}_{2}$ plasma & $403.6 \pm 9.1$ & $16.4 \pm 0.1$ & $223.0 \pm 3.7$ \\
\hline $\mathrm{N}_{2}$ plasma & $368.1 \pm 26.3$ & $15.7 \pm 0.7$ & $196.0 \pm 9.1$ \\
\hline
\end{tabular}

Figure 3 and Table 2 show the wicking results of untreated and plasma treated samples. The wicking of cotton increases after treatment with plasma, regardless of the working gas 
used. The differences in wicking height between untreated and plasma treated samples are already evident in the wicking measured after $30 \mathrm{~s}$, as it increases from $33.5 \pm 0.12 \mathrm{~mm}$ for the untreated sample to $38.5 \pm 0.07 \mathrm{~mm}$ for the $\mathrm{O}_{2}$ plasma treated sample and to $38.0 \pm 0.07 \mathrm{~mm}$ for the $\mathrm{N}_{2}$ plasma treated sample. The higher absorptivity of the plasma treated cotton samples becomes more evident after $300 \mathrm{~s}$ of measurement, where the difference between the heights of the capillary rise of the untreated and plasma treated cotton is $9 \mathrm{~mm}$. Since the wicking of a substrate is directly related to the hydrophilicity of the substrate, it is clear from the results that both plasma treatments, regardless of the gas used $\left(\mathrm{O}_{2}\right.$ or $\left.\mathrm{N}_{2}\right)$, increase the ability of the cotton to absorb water.

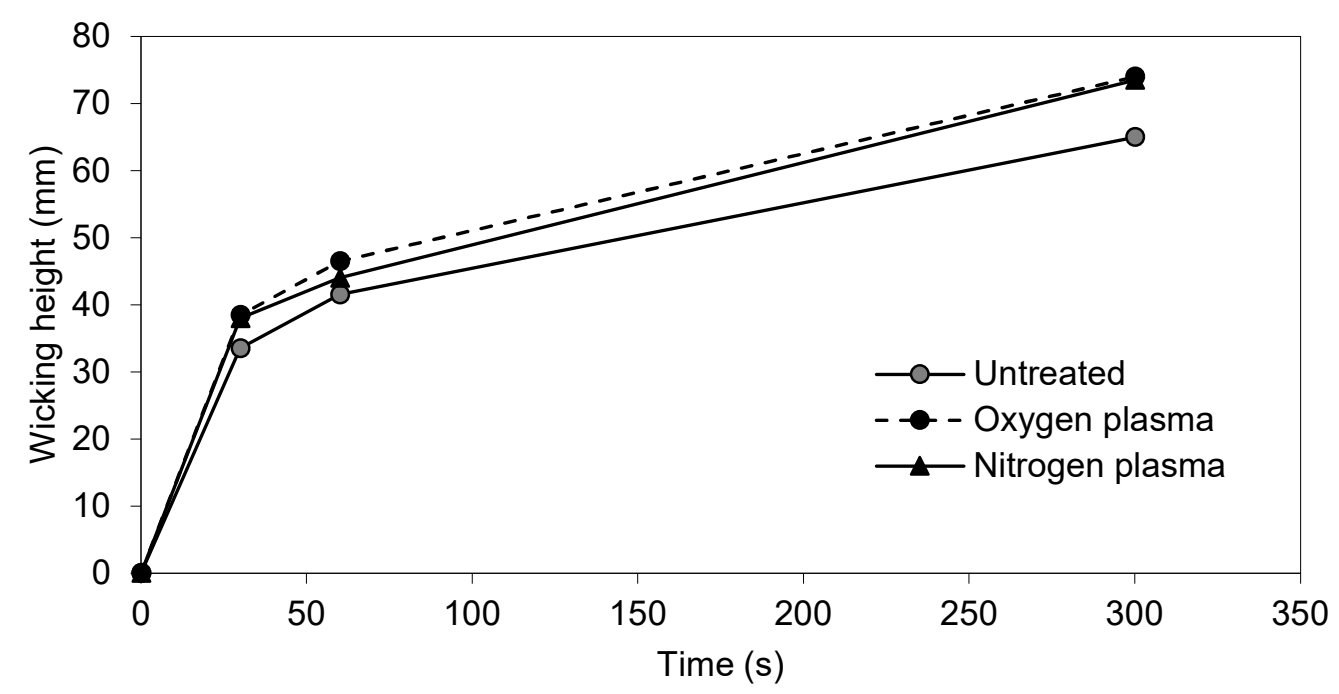

Figure 3. Wicking height (mm) of untreated and plasma treated samples after 30, 60, and $300 \mathrm{~s}$.

Table 2. Wicking height $(\mathrm{mm})$ of untreated and plasma-treated cotton samples measured after 30, 60, and $300 \mathrm{~s}$.

\begin{tabular}{cccc}
\hline \multirow{2}{*}{ Sample } & \multicolumn{3}{c}{ Wicking Height (mm) } \\
\cline { 2 - 4 } & $\mathbf{3 0 ~}$ & $\mathbf{6 0 ~ s}$ & $\mathbf{3 0 0 ~ s}$ \\
\hline Untreated & $33.5 \pm 0.12$ & $41.5 \pm 0.13$ & $65.0 \pm 0.11$ \\
\hline $\mathrm{O}_{2}$ plasma & $38.5 \pm 0.07$ & $46.5 \pm 0.12$ & $74.0 \pm 0.07$ \\
\hline $\mathrm{N}_{2}$ plasma & $38.0 \pm 0.07$ & $44.0 \pm 0.11$ & $73.5 \pm 0.07$ \\
\hline
\end{tabular}

The untreated, $\mathrm{O}_{2}$ plasma treated and $\mathrm{N}_{2}$ plasma-treated cotton fabrics were coated with fragrance microcapsules (FCM). The effect of plasma on adsorption and adhesion of microcapsules was monitored by SEM, air permeability, and fragrance intensity after repeated washing. The morphology of the cotton samples coated with microcapsules is shown in Figure 4. The difference between the untreated and plasma treated samples is obvious. Both gases used for cotton treatment caused changes that allowed higher adsorption of FCM (Figure $4 \mathrm{~b}, \mathrm{c}$ ). In addition, the incorporation of positively charged functional groups on the fabric surface, which was achieved by the $\mathrm{N}_{2}$ plasma treatment, could increase the adsorption of the negatively charged acrylic binder due to electrostatic attractive interactions, which could be reflected in a higher amount of microcapsules adsorbed on the cotton fabric. The increased adsorption of microcapsules on $\mathrm{N}_{2}$ plasmatreated fabric is evident from Figure 4c. 


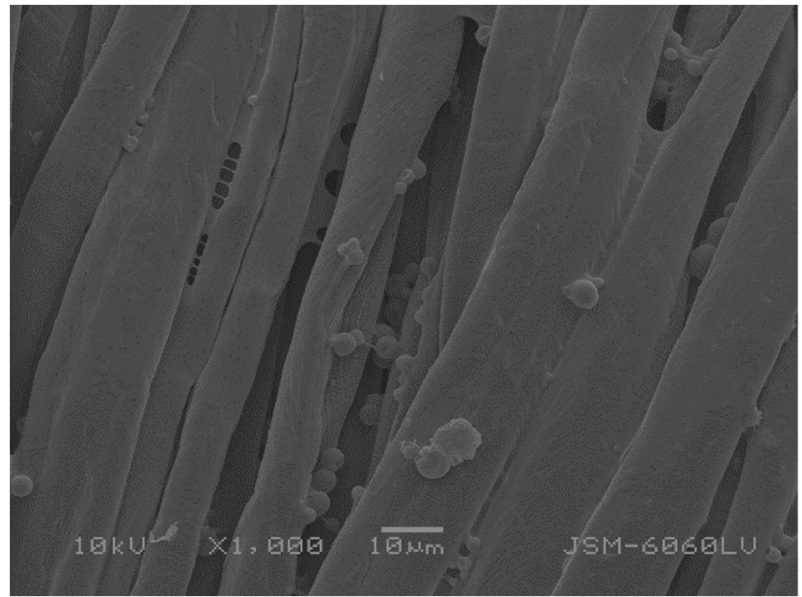

(a)

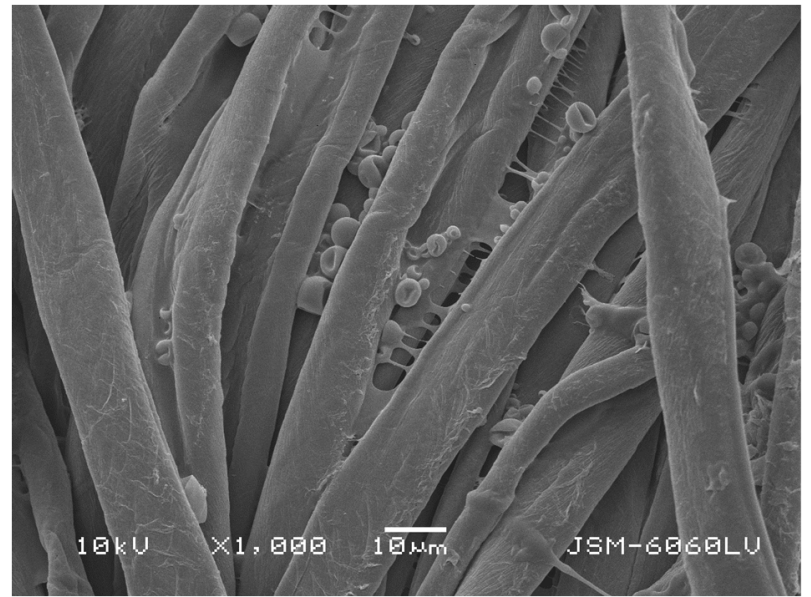

(b)

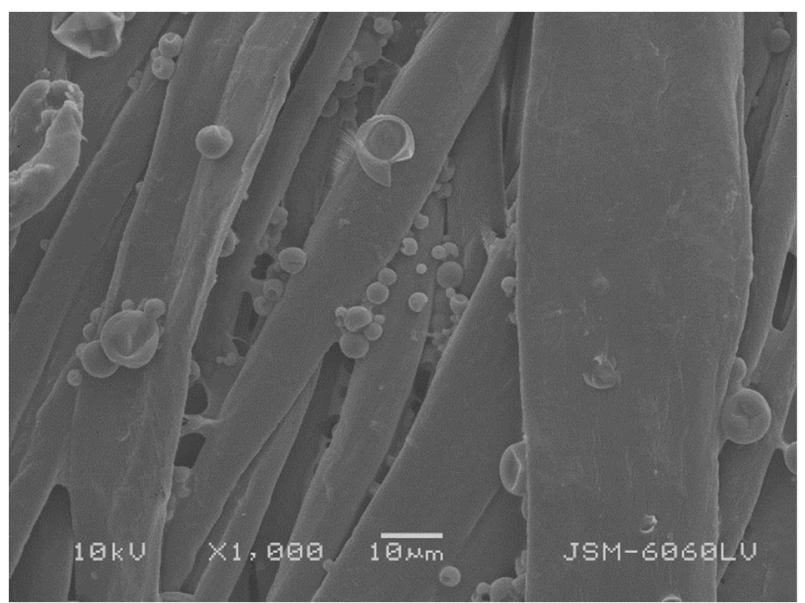

(c)

Figure 4. SEM images of (a) untreated, (b) $\mathrm{O}_{2}$ plasma-treated, and (c) $\mathrm{N}_{2}$ plasma-treated samples of cotton fabric impregnated with fragrance microcapsules.

The adsorption and adhesion of FCM on cotton fabric was evaluated measuring the air permeability of the fabric. The results presented in Figure 5 and Table 3 show that untreated and FCM-coated fabric is more air permeable than plasma-treated and FCMcoated fabrics. The lowest air permeability was found for the $\mathrm{N}_{2}$ plasma-treated and FCM-coated sample $(435.9 \pm 8.5 \mathrm{~mm} / \mathrm{s})$, and the highest for the untreated and FCM-coated sample ( $457.2 \pm 12.3 \mathrm{~mm} / \mathrm{s})$ (Table 3$)$. The decrease of the air permeability is attributed to the binder layer that forms during the curing process and closes the voids between the fibers and consequently between warp and weft yarns of the fabric. It must be emphasized that not only binder layer, but also microcapsules themselves may contribute to lower air permeability. Since the lowest air permeability is obtained for the $\mathrm{N}_{2}$ plasma treated and FCM-coated fabric, this indicates that this sample contains the highest amount of FCM. After repeated washing (i.e., 1, 5, and 10), the air permeability gradually increases for all samples as the binder layer is slowly removed, thus removing the microcapsules that were trapped in the binding layer. The removal of the FCM and binding layer was also confirmed by SEM (Figure 6). After the tenth wash, the least amount of FCM is visible on the surface of untreated and FCM-coated sample (Figure 6a). The voids between the fibers are almost completely free of the binder layer. The sample treated with $\mathrm{O}_{2}$ plasma and coated with FCM has visible few smaller microcapsules on the surface after the tenth wash (Figure $6 b$ ). Here the binder layer between the fibers is more pronounced compared to the untreated and FCM-coated sample (Figure 6a). Also, the etching effect of the $\mathrm{O}_{2}$ plasma is still visible as the fibrils protrude from the fibers surface (Figure $6 \mathrm{~b}$ ). The $\mathrm{N}_{2}$ plasma-treated and FCM-coated sample has visibly the highest amount of microcapsules on the surface 
after the tenth wash of all samples (Figure 6c). Many different size microcapsules are still attached to the fiber surface and are accompanied by the binder layer on and between the fibers. The removal of microcapsules and binder layer was attributed to mechanical action and abrasion between the stainless-steel balls and the sample during washing process. Since air permeability is lowest for the $\mathrm{N}_{2}$ plasma-treated and FCM-coated sample, this indicates good wash resistance due to the higher adhesion of the microcapsules and binder layer compared to the untreated or $\mathrm{O}_{2}$ plasma-treated sample. This observation is also in good agreement with the results reported in the literature. The adsorption and adhesion of various substances, e.g., silica [54], ink [55], copper [56], or even human monocytes [57] on polypropylene was enhanced after plasma treatment, and it was found that the adhesion was higher for $\mathrm{N}_{2}$ plasma than for $\mathrm{O}_{2}$ plasma-treated polymer. This is interesting as it is well documented that higher adhesion between materials is achieved by high surface roughness due to mechanical interlocking. From our results and reports in the literature, it can be concluded that nitrogen-rich functional groups (grafted onto the polymer surface) serve as binding sites for adsorption and electrostatic interactions for microcapsule adhesion.

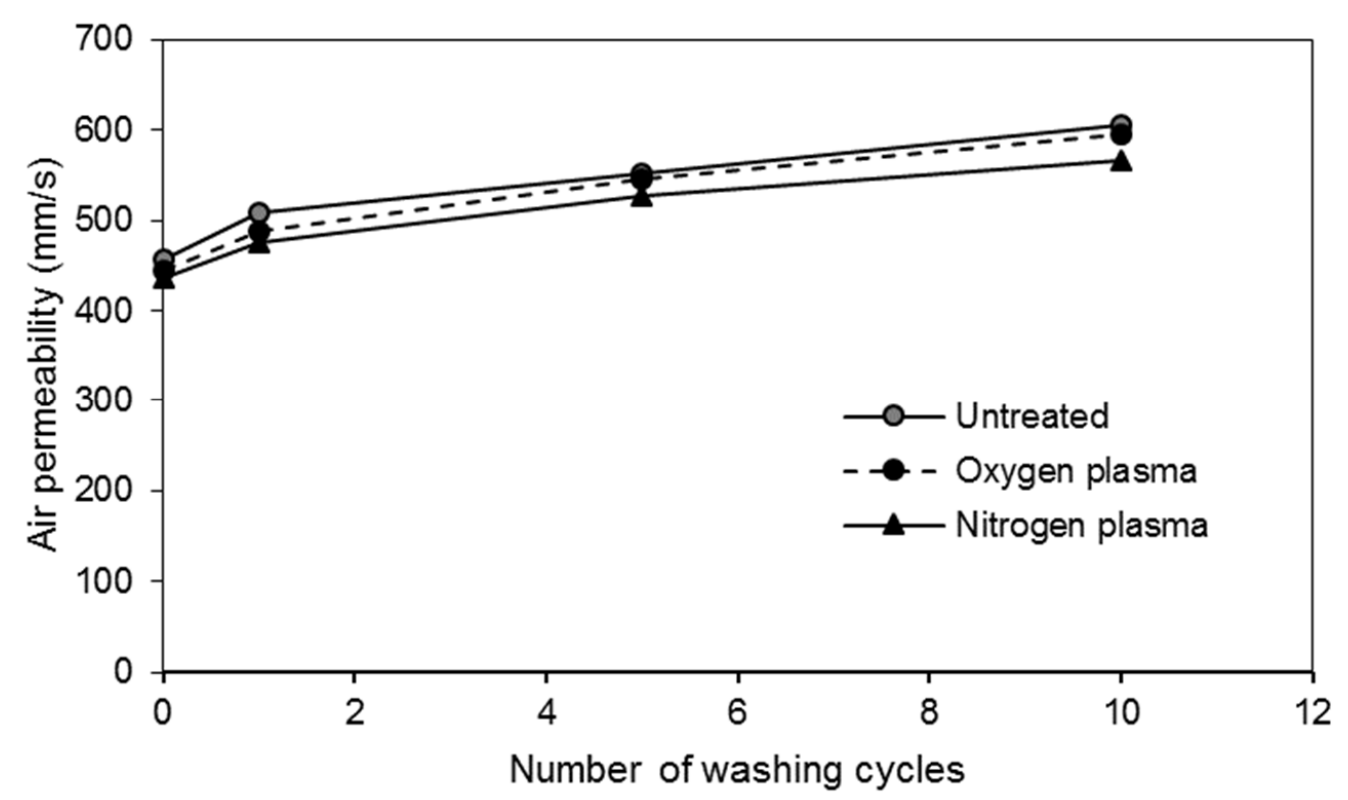

Figure 5. Air permeability $(\mathrm{mm} / \mathrm{s})$ of untreated and plasma-treated microcapsule-coated cotton fabrics before (zero number of washing) and after washing (one, five, and ten numbers of washing).

Table 3. Air permeability ( $\mathrm{mm} / \mathrm{s})$ of untreated and plasma-treated microcapsule-coated cotton samples before $(0 \mathrm{w})$ and after washing $(1 \mathrm{w}, 5 \mathrm{w}$, and $10 \mathrm{w})$.

\begin{tabular}{ccccc}
\hline \multirow{2}{*}{ Sample } & \multicolumn{4}{c}{ Air Permeability $\mathbf{( m m / s )}$} \\
\cline { 2 - 5 } & $\mathbf{0 ~ w}$ & $\mathbf{1 ~ w}$ & $\mathbf{5 ~ w}$ & $\mathbf{1 0 ~ w}$ \\
\hline Untreated + FCM & $457.2 \pm 12.3$ & $508.9 \pm 13.1$ & $552.4 \pm 10.6$ & $605.8 \pm 5.1$ \\
\hline $\mathrm{O}_{2}$ plasma + FCM & $444.2 \pm 10.6$ & $488.9 \pm 12.5$ & $545.7 \pm 3.1$ & $595.5 \pm 6.12$ \\
\hline $\mathrm{N}_{2}$ plasma + FCM & $435.9 \pm 8.5$ & $475.5 \pm 9.5$ & $526.9 \pm 2.23$ & $566.0 \pm 1.4$ \\
\hline
\end{tabular}




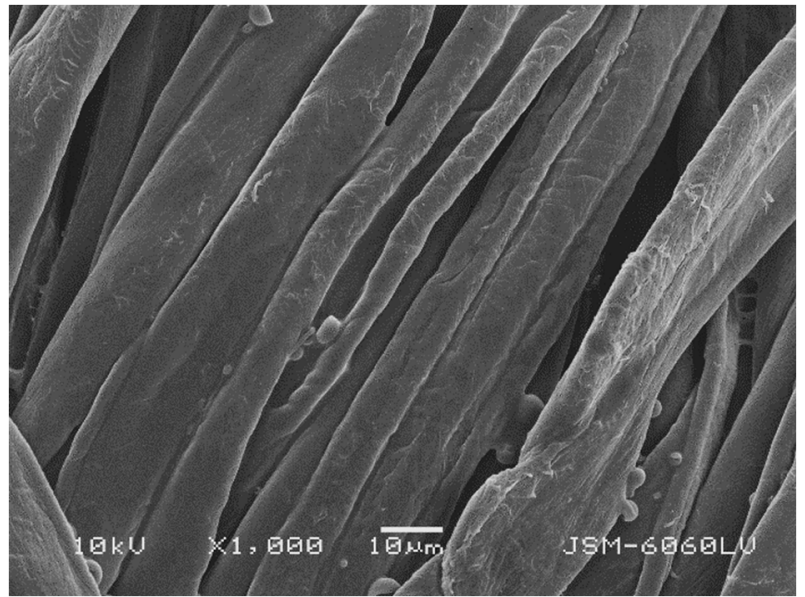

(a)

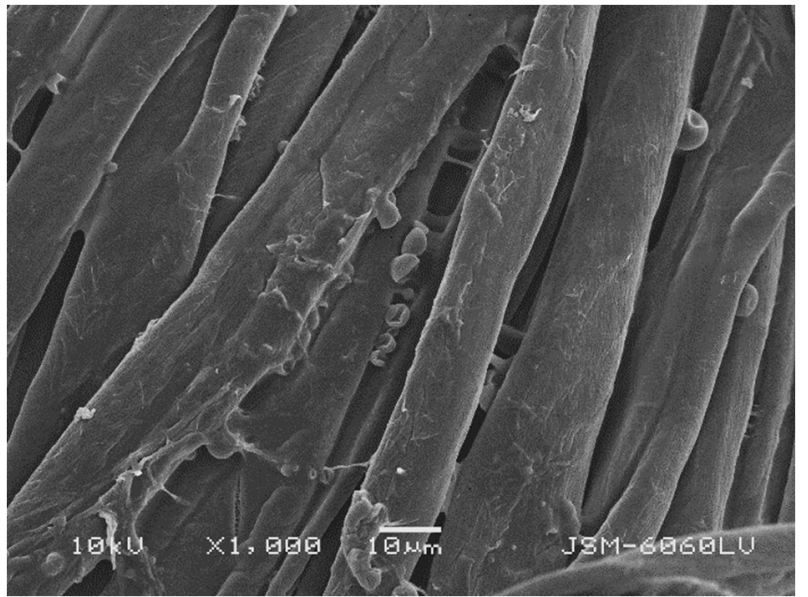

(b)

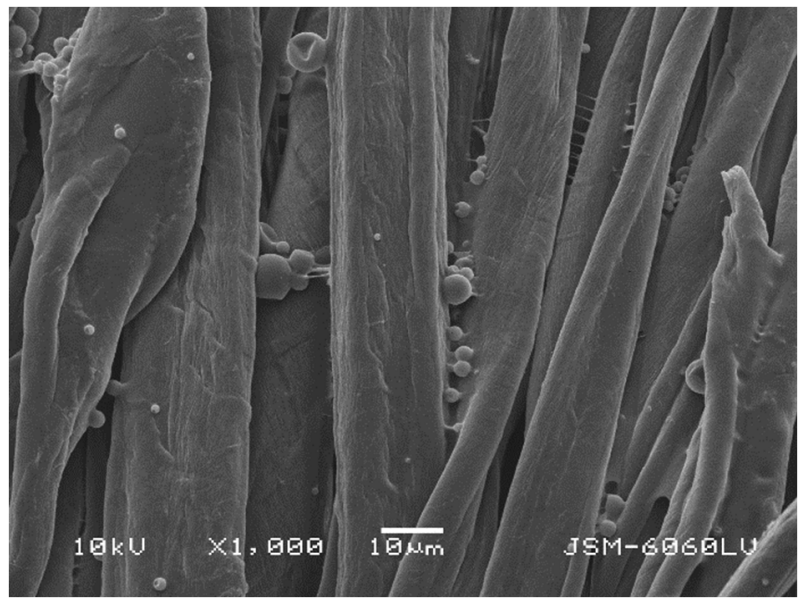

(c)

Figure 6. SEM images of (a) untreated and FCM-coated sample, (b) $\mathrm{O}_{2}$ plasma-treated and FCM-coated sample, and (c) $\mathrm{N}_{2}$ plasma treated and FCM-coated sample after tenth wash.

The adhesion of FCM on cotton was additionally evaluated with the fragrance intensity of the functionalized fabric. The fragrance evaluation results, which are summarized in Table 4, show that the fragrance intensity of untreated and FCM-coated sample is strong, but gradually decreases with increasing number of washing cycles and completely disappears after 10 washing cycles. The same observation was made for $\mathrm{O}_{2}$ plasma-treated and FCMcoated fabric, while $\mathrm{N}_{2}$ plasma-treated and FCM-coated samples still contained a strong fragrance after 5 wash cycles. In the case of the $\mathrm{N}_{2}$ plasma-treated and FCM-coated sample, the fragrance remained after 10 wash cycles, although somewhat weaker. The absence of the fragrance of untreated and $\mathrm{O}_{2}$ plasma-treated and FCM-coated samples after repetitive washing is due to the removal of binder layer with entrapped FCM, as mentioned earlier. Although some microcapsules are still visible on the surface of these two samples after the tenth wash (Figure 6a,b), their quantity is so low and only very small microcapsules were present that most judges classified the samples as fragrance-free.

FTIR analysis provided additional—spectral—information about the behavior and properties between the untreated and plasma-treated samples, which were uncoated and FCM-coated. Since six recorded spectra are generally very similar to each other, differing significantly only in the absorption peaks at a few specific wavenumbers (Figure 7), PCA was used to visualize and interpret these differences. 
Table 4. Fragrance intensity of unwashed and washed microcapsule-coated cotton fabrics expressed as number of responses for each treatment.

\begin{tabular}{|c|c|c|c|c|c|}
\hline \multirow{2}{*}{ Sample } & \multirow{2}{*}{$\begin{array}{l}\text { Number of } \\
\text { Wash Cycles }\end{array}$} & \multicolumn{4}{|c|}{ Fragrance Intensity } \\
\hline & & Strong & Medium & Weak & Absent \\
\hline Control * & & 0 & 0 & 0 & 30 \\
\hline Untreated & & 30 & 0 & 0 & 0 \\
\hline $\mathrm{O}_{2}$ plasma & 0 & 30 & 0 & 0 & 0 \\
\hline $\mathrm{N}_{2}$ plasma & & 30 & 0 & 0 & 0 \\
\hline Untreated & & 2 & 28 & 0 & 0 \\
\hline $\mathrm{O}_{2}$ plasma & 1 & 3 & 27 & 0 & 0 \\
\hline $\mathrm{N}_{2}$ plasma & & 29 & 1 & 0 & 0 \\
\hline Untreated & & 0 & 5 & 25 & 0 \\
\hline $\mathrm{O}_{2}$ plasma & 5 & 0 & 3 & 27 & 0 \\
\hline $\mathrm{N}_{2}$ plasma & & 26 & 4 & 0 & 0 \\
\hline Untreated & & 0 & 0 & 1 & 29 \\
\hline $\mathrm{O}_{2}$ plasma & 10 & 0 & 0 & 2 & 28 \\
\hline $\mathrm{N}_{2}$ plasma & & 1 & 27 & 2 & 0 \\
\hline
\end{tabular}

* Control sample was not coated with fragrance microcapsules.

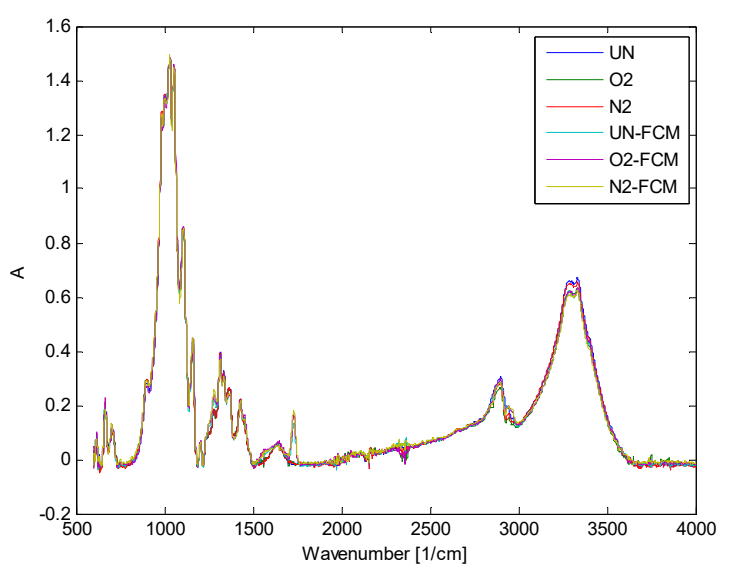

(a)

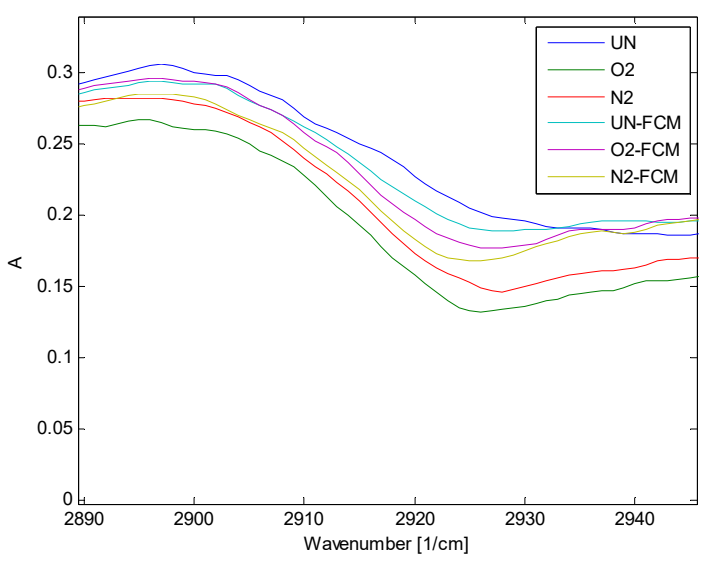

(c)

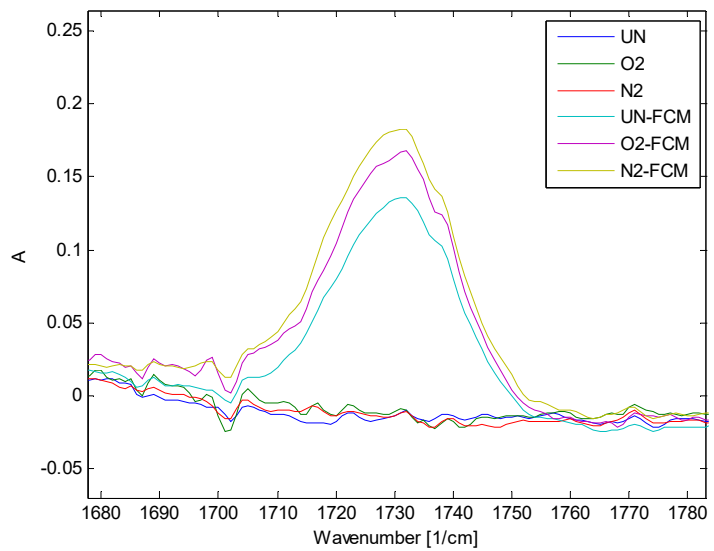

(b)

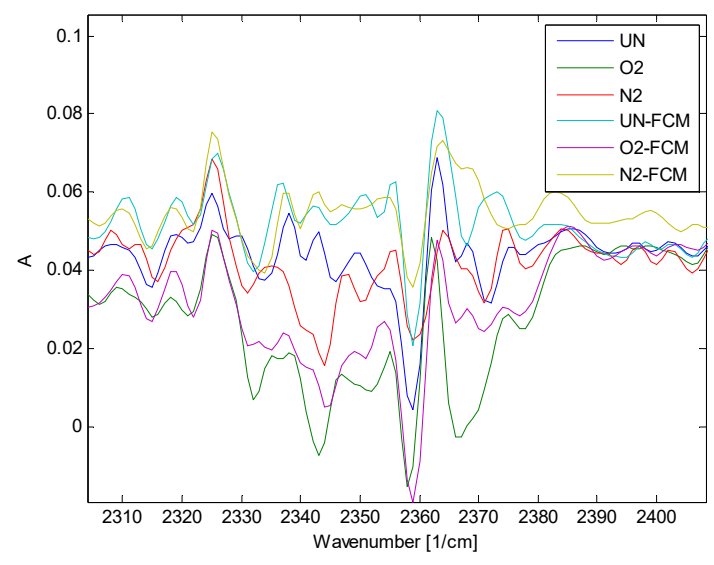

(d)

Figure 7. The (a) original FTIR spectra and $(\mathbf{b}-\mathbf{d})$ magnified views of three regions with most pronounced differences among the samples.

Figures $8 \mathrm{a}$ and $9 \mathrm{a}$ show score plots, i.e., relationships between the six samples under investigation, while Figures $8 \mathrm{~b}-\mathrm{d}$ and $9 \mathrm{~b}-\mathrm{d}$ show loading plots, i.e., correlations between the original variables (wavenumbers) and the first three PCs. 


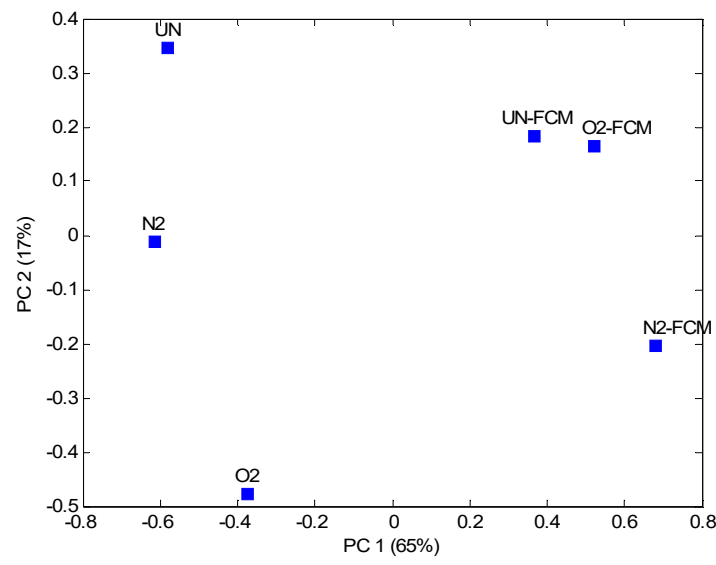

(a)

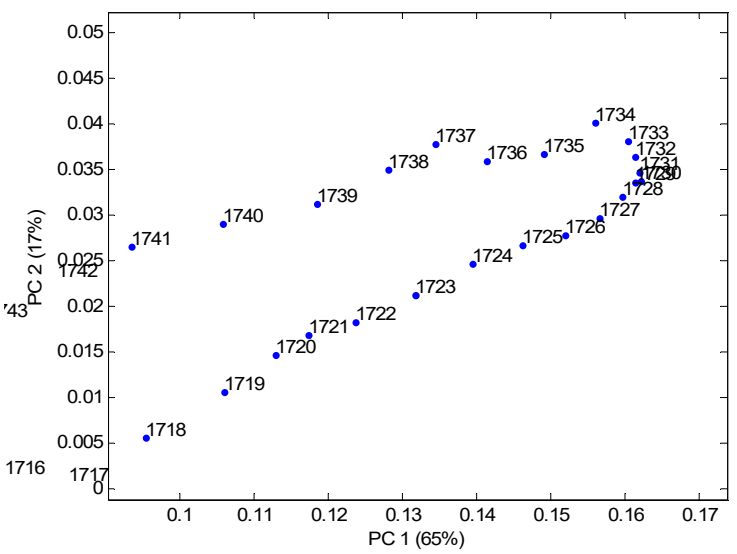

(c)

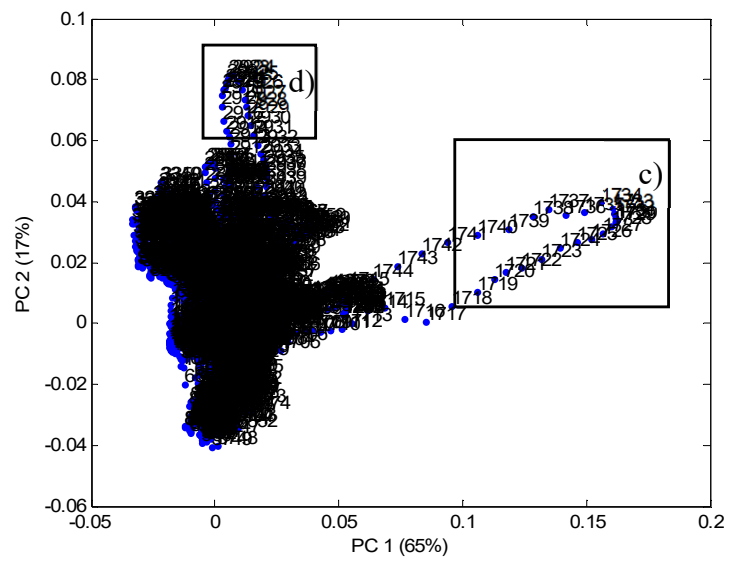

(b)

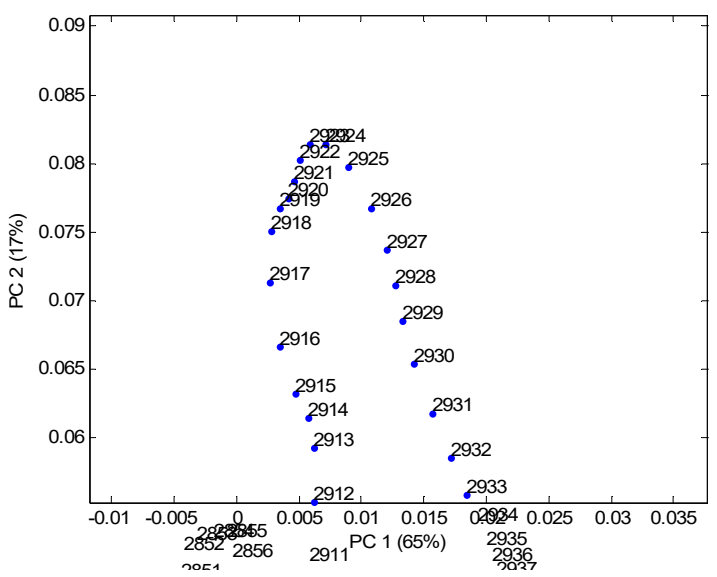

(d)

Figure 8. PC1-PC2 score plot (a) and PC1-PC2 loading plots (b-d).

A closer look at the original spectral data shows that the most striking difference between the uncoated and FCM-coated samples is the presence or absence of an absorption peak at wavenumber $1730 \mathrm{~cm}^{-1}$ (see Figure $7 \mathrm{~b}$ ). The PC1-PC2 score and loading plots-Figure $8 \mathrm{a}-\mathrm{c}-$ confirm this fact. PC1, which accounts for most of the FTIR information $(65 \%)$, distributes the samples horizontally from left to right according to their absorption at that wavelength (the rightmost data point in Figure 8c). While the uncoated samples on the left $\left(\mathrm{UN}, \mathrm{O}_{2}, \mathrm{~N}_{2}\right.$ ) show no absorption, the three samples coated with FCM (UN-FCM, $\mathrm{O}_{2}$-FCM, $\mathrm{N}_{2}$-FCM) show strong peaks at this wavenumber. Moreover, the intensity peak of sample $\mathrm{N}_{2}$-FCM is the highest, followed by samples $\mathrm{O}_{2}-\mathrm{FCM}$ and UN-FCM, which means that more FCM was adsorbed on the cotton fabric after treatment with $\mathrm{N}_{2}$ plasma. The absorption intensity of each sample corresponds to its horizontal constellation in Figure 8a. The samples also differ, albeit less clearly, in terms of their absorption intensity in the wavenumber region between $2915-2930 \mathrm{~cm}^{-1}$ (see Figure 7c). Accordingly, the vertical-i.e., along PC2-position of the samples in the PC1-PC2 score plot (Figure 8a) corresponds exactly to their absorption values at $2924 \mathrm{~cm}^{-1}$ : the untreated sample (UN) has the highest absorption, followed by UN-FCM, $\mathrm{O}_{2}-\mathrm{FCM}$, etc., while $\mathrm{O}_{2}$ is characterized by the lowest absorption intensity. Finally, PC3, which accounts for only $10 \%$ of all spectral information, arranges the samples according to their absorption intensity in the $2330-2380 \mathrm{~cm}^{-1}$ region. As shown by the similarity of the positions of the samples and wavenumbers in Figure 9a,d, the absorption is strongest for the $\mathrm{N}_{2}$-FCM sample (upper regions of both plots) and decreases towards $\mathrm{O}_{2}-\mathrm{FCM}$, which has the lowest absorption. These results are consistent with previous ones (i.e., SEM, fragrance intensity, and air 
permeability). Examining the two score plots, one can assign a physical mean to two of the first three PCs. As mentioned above, PC1-the horizontal axis in Figure 8a-is related to the presence $\left(\mathrm{N}_{2}-\mathrm{FCM}, \mathrm{O}_{2}-\mathrm{FCM}, \mathrm{UN}-\mathrm{FCM}\right)$ or absence of microcapsules $\left(\mathrm{N}_{2}, \mathrm{O}_{2}, \mathrm{UN}\right)$ on the samples. On the other hand, $\mathrm{PC} 3$ - the vertical axis in Figure 9a-separates the samples in terms of presence and type of plasma treatment: in the upper part of the diagram, we find both $\mathrm{N}_{2}$ plasma-treated samples $\left(\mathrm{N}_{2}-\mathrm{FCM}\right.$ and $\mathrm{N}_{2}$ ), untreated samples ( $\mathrm{UN}$ and $\mathrm{UN}-\mathrm{FCM})$ are located in the middle, while both $\mathrm{O}_{2}$ plasma-treated samples $\left(\mathrm{O}_{2}, \mathrm{O}_{2}-\mathrm{FCM}\right)$ are found in the lower part of the diagram.

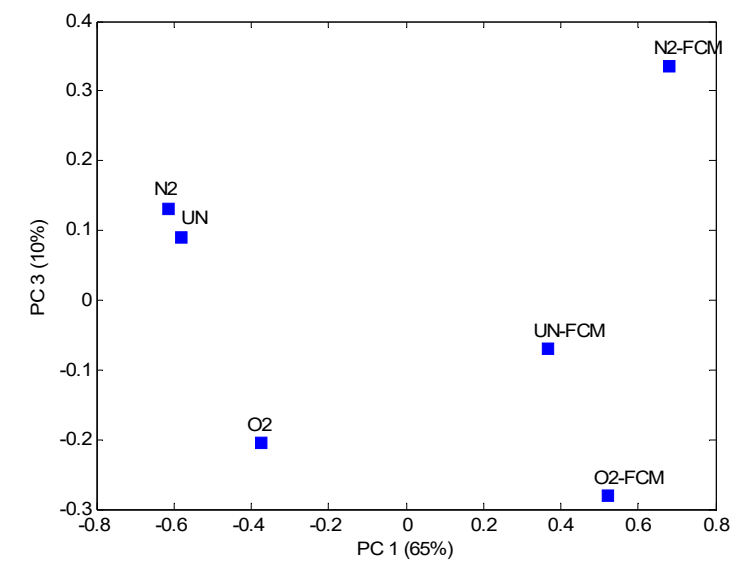

(a)

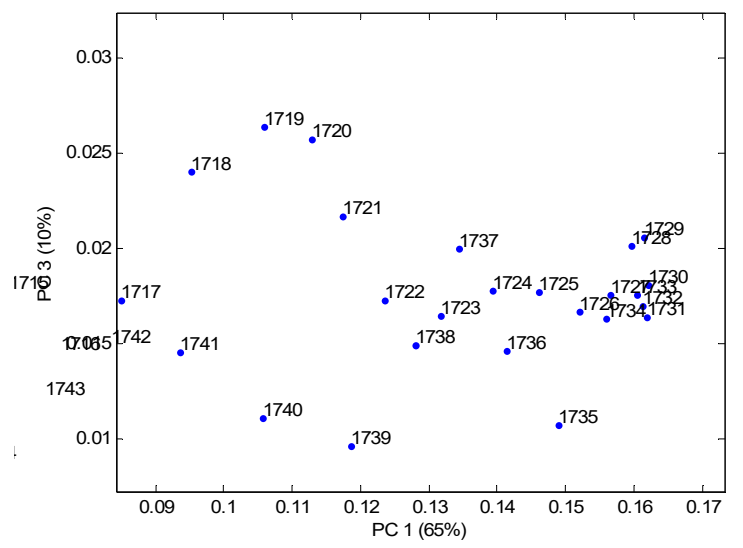

(c)

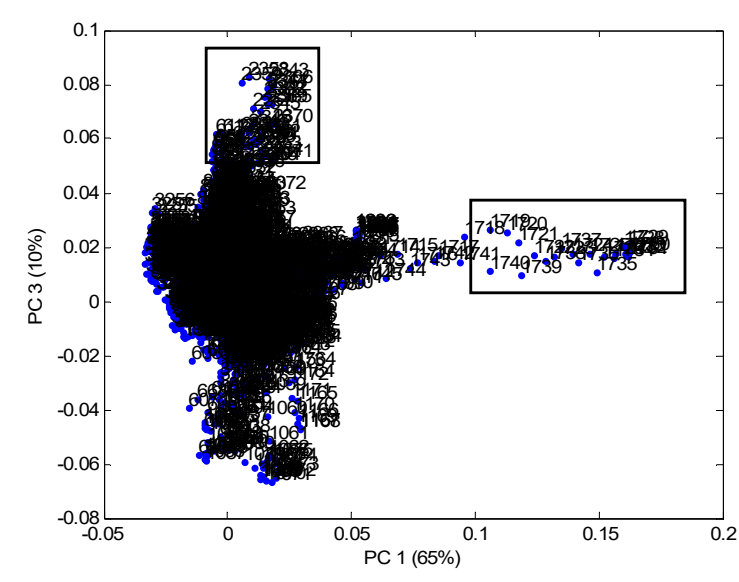

(b)

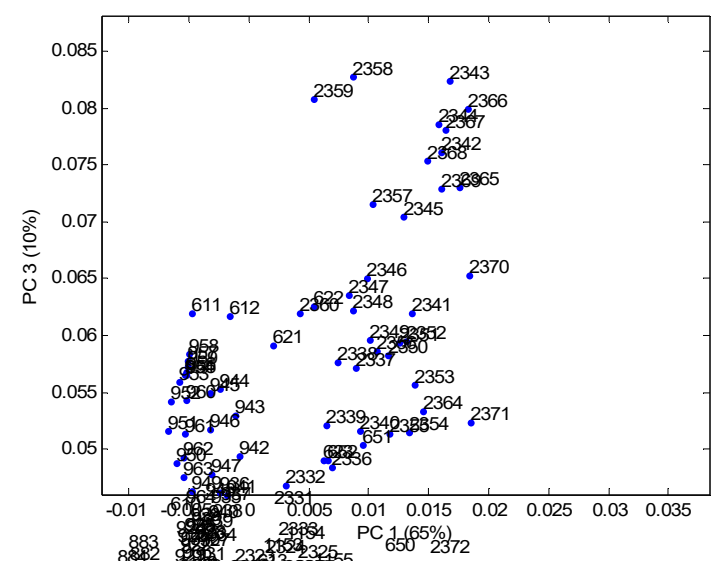

(d)

Figure 9. PC1-PC3 score plot (a) and PC1-PC3 loading plots (b-d).

\section{Conclusions}

In this study, cotton fabric was treated with a low-pressure capacitively coupled plasma system using oxygen or nitrogen gases and coated with fragrance microcapsules (FCM). The effect of plasma treatment was evaluated with SEM, the mechanical properties and wicking ability of the fabric, the adsorption of FCM on cotton with SEM and FTIR, and the adsorption and adhesion of FCM on cotton with the SEM, air permeability, and fragrance intensity after repetitive domestic washing. The results show that the plasma treatment with either of the two gases induces chemical surface changes of cotton, which allows higher adsorption of FCM. The higher etch rate of the $\mathrm{O}_{2}$ plasma compared to the $\mathrm{N}_{2}$ plasma also leads to changes in the morphology of the fibers, resulting in better interlocking of cellulose fibrils protruding from the fiber surface and increased tensile strength. The wicking ability of the plasma treated cotton fabric increased by $14 \%$ due to the incorporation of polar functional groups on the fiber surface. This allowed higher adsorption of FCM on fabrics, which was demonstrated by SEM, FTIR, and air permeability. 
The air permeability and fragrance intensity of the samples slowly decreased after repeated washing. The $\mathrm{N}_{2}$ plasma-treated and FCM-coated sample showed medium fragrance intensity and lower air permeability even after ten domestic washes, while the untreated and $\mathrm{O}_{2}$ plasma-treated and FCM-coated samples showed almost no fragrance and higher air permeability. The grafting of nitrogen-rich groups onto the cellulose surface with $\mathrm{N}_{2}$ plasma allows binding sites and electrostatic interactions with the anionic coating, which enable adsorption and adhesion. For further research, the different nitrogen-rich gases (i.e., $\mathrm{N}_{2}, \mathrm{NH}_{3}$ ) or their mixtures should be investigated for plasma generation to evaluate the optimal conditions for plasma treatment and careful design of textiles with microcapsules-enhanced wash resistance.

Author Contributions: Conceptualization, M.G. and N.P.; Methodology, M.G. and Z.L.P.; Formal analysis, M.G. and K.S.; Investigation, M.K., M.G., K.S. and N.P.; Resources, Z.L.P., P.F.T. and M.G.; Data curation, A.H.; Writing—original draft preparation, M.K., M.G., A.H. and N.P.; Writing—review and editing, M.K., P.F.T., Z.L.P., K.S. and N.P.; Visualization, M.K.; Supervision, M.G.; Funding acquisition, M.G., N.P., K.S. and Z.L.P. All authors have read and agreed to the published version of the manuscript.

Funding: The work was supported by Slovenian Research Agency (P2-0213, RIC UL-NTF, bilateral project). K.S. and N.P. are supported by MESTD of Republic of Serbia grant No. 451-03-68/2021$14 / 200024$.

Institutional Review Board Statement: Not applicable.

Informed Consent Statement: Not applicable.

Data Availability Statement: Data sharing is not applicable to this article.

Conflicts of Interest: The authors declare no conflict of interest.

\section{References}

1. Cerempei, A. Aromatherapeutic textiles. In Active Ingredients from Aromatic and Medicinal Plants; El-Shemy, H.A., Ed.; InTech: Rijeka, Croatia, 2017; pp. 87-106.

2. Singh, N.; Sheikh, J. Microencapsulation and its application in production of functional textiles. Indian J. Fibre Text 2020, 45, 495-509.

3. Ghayempour, S.; Montazer, M. Micro/nanoencapsulation of essential oils and fragrances: Focus on perfumed, antimicrobial, mosquito-repellent and medical textiles. J. Microencapsul. 2016, 33, 497-510. [CrossRef]

4. Xiao, B.; Wang, W.; Zhang, X.; Long, G.; Fan, J.; Chen, H.; Deng, L. A novel fractal solution for permeability and Kozeny-Carman constant of fibrous porous media made up of solid particles and porous fibers. Powder Technol. 2019, 349, 92-98. [CrossRef]

5. Cristina, E.D. Understanding true aromatherapy: Understanding essential oils. Home Health Care Manag. Pract. 2004, 16, 474-479. [CrossRef]

6. Bonet-Aracil, M.; Monllor, P.; Capablanca, L.; Gisbert, J.; Díaz, P.; Montava, I. A comparison between padding and bath exhaustion to apply microcapsules onto cotton. Cellulose 2015, 22, 2117-2127. [CrossRef]

7. Bezerra, F.M.; Carmona, O.G.; Carmona, C.G.; Lis, M.J.; de Moraes, F.F. Controlled release of microencapsulated citronella essential oil on cotton and polyester matrices. Cellulose 2016, 23, 1459-1470. [CrossRef]

8. Boh, B.; Knez, E. Microencapsulation of essential oils and phase change materials for applications in textile products. Indian J. Fibre Text. Res. 2006, 31, 72-82.

9. Bonet-Aracil, M.; Capablanca, L.; Monllor, P.; Díaz, P.; Montava, I. Studying bath exhaustion as a method to apply microcapsules on fabrics. J. Text. Inst. 2012, 103, 629-635. [CrossRef]

10. Golja, B.; Šumiga, B.; Tavčer, P.F. Fragrant finishing of cotton with microcapsules: Comparison between printing and impregnation. Color. Technol. 2013, 129, 338-346. [CrossRef]

11. Li, S.; Boyter, H.; Qian, L. UV curing for encapsulated aroma finish on cotton. J. Text. Inst. 2005, 96, 407-411. [CrossRef]

12. Li, S.; Lewis, J.E.; Stewart, N.M.; Qian, L.; Boyter, H. Effect of finishing methods on washing durability of microencapsulated aroma finishing. J. Text. Inst. 2008, 99, 177-183. [CrossRef]

13. Oliveira, F.R.; Fernandes, M.; Carneiro, N.; Souto, A.P. Functionalization of wool fabric with phase-change materials microcapsules after plasma surface modification. J. Appl. Polym. Sci. 2013, 128, 2638-2647. [CrossRef]

14. Ghayempour, S.; Mortazavi, S.M. Microwave curing for applying polymeric nanocapsules containing essential oils on cotton fabric to produce antimicrobial and fragrant textiles. Cellulose 2015, 22, 4065-4075. [CrossRef]

15. Carmo, S.N.D.; Zille, A.; Souto, A.P. Plasma-assisted deposition of microcapsule containing Aloe vera extract for cosmeto-textiles. IOP Conf. Ser. Mater. Sci. Eng. 2017, 254, 122007. [CrossRef] 
16. Guignard, M.I.; Campagne, C.; Giraud, S.; Brebu, M.; Vrinceanu, N.; Cioca, L.-I. Functionalization of a bamboo knitted fabric using air plasma treatment for the improvement of microcapsules embedding. J. Text. Inst. 2014, 106, 119-132. [CrossRef]

17. Shin, S.; Shin, J.E.; Yoo, Y.J. Attachment of alginate microcapsules onto plasma-treated PDMS sheet for retrieval after transplantation. Biotechnol. Appl. Biochem. 2013, 60, 617-622. [CrossRef] [PubMed]

18. Oliveira, F.R.; Silva, E.A.A.; Carmo, S.N.D.; Steffens, F.; Souto, A.P.G.D.V. Functionalization of natural cork composite with microcapsules after plasma treatment. Adv. Mater. Sci. Eng. 2014, 2014, 685829. [CrossRef]

19. Park, S.-J.; Kim, K.-S. Effect of oxygen plasma treatment on the release behaviors of poly (E-caprolactone) microcapsules containing tocopherol. Colloids Surf. B Biointerfaces 2005, 43, 138-142. [CrossRef] [PubMed]

20. Gorjanc, M.; Mozetič, M.; Vesel, A.; Zaplotnik, R. Natural dyeing and UV protection of plasma treated cotton. Eur. Phys. J. D 2018, 72, 41. [CrossRef]

21. Štular, D.; Primc, G.; Mozetič, M.; Jerman, I.; Mihelčič, M.; Ruiz-Zepeda, F.; Tomšič, B.; Simončič, B.; Gorjanc, M. Influence of non-thermal plasma treatement on the adsorption of a stimuli-responsive nanogel onto polyethylene terephthalate fabric. Prog. Org. Coat. 2018, 120, 198-207. [CrossRef]

22. Gorjanc, M.; Savić, A.; Topalić-Trivunović, L.; Mozetič, M.; Zaplotnik, R.; Vesel, A.; Grujić, D. Dyeing of plasma treated cotton and bamboo rayon with Fallopia japonica extract. Cellulose 2016, 23, 2221-2228. [CrossRef]

23. Primc, G.; Tomšič, B.; Vesel, A.; Mozetič, M.; Ražić, S.E.; Gorjanc, M. Biodegradability of oxygen-plasma treated cellulose textile functionalized with $\mathrm{ZnO}$ nanoparticles as antibacterial treatment. J. Phys. D Appl. Phys. 2016, 49, 324002. [CrossRef]

24. Sun, Z.; Zhou, Y.; Li, W.; Chen, S.; You, S.; Ma, J. Preparation of silver-plated para-aramid fiber by employing low-temperature oxygen plasma treatment and dopamine functionalization. Coatings 2019, 9, 599. [CrossRef]

25. Ribeiro, A.I.; Senturk, D.; Silva, K.K.; Modic, M.; Cvelbar, U.; Dinescu, G.; Mitu, B.; Nikiforov, A.; Leys, C.; Kuchakova, I.; et al. Antimicrobial efficacy of low concentration PVP-silver nanoparticles deposited on DBD plasma-treated polyamide 6,6 fabric. Coatings 2019, 9, 581. [CrossRef]

26. Radetić, M.; Jocić, D.; Jovančić, P.; Rajaković, L.; Thomas, H.; Petrović, Z.L. Recycled-wool-based nonwoven material as a sorbent for lead cations. J. Appl. Polym. Sci. 2003, 90, 379-386. [CrossRef]

27. Radetić, M.M.; Jocić, D.M.; Jovančić, P.; Petrović, Z.; Thomas, H.F. Recycled wool-based nonwoven material as an oil sorbent. Environ. Sci. Technol. 2003, 37, 1008-1012. [CrossRef]

28. Mihailović, D.; Saponjic, Z.; Molina, R.; Puac, N.; Jovančić, P.; Nedeljkovic, J.; Radetić, M. Improved properties of oxygen and argon RF plasma-activated polyester fabrics loaded with $\mathrm{TiO}_{2}$ nanoparticles. ACS Appl. Mater. Interfaces 2010, 2, 1700-1706. [CrossRef]

29. Makabe, T.; Petrović, Z.L. Plasma Electronics: Applications in Microelectronic Device Fabrication, 2nd ed.; CRC Press: New York, NY, USA, 2015; 360p.

30. Lieberman, M.A.; Lichtenberg, A.J. Principles of Plasma Discharges and Materials Processing; Wiley: Hoboken, NJ, USA, 2005.

31. Chabert, P.; Braithwaite, N. Physics of Radio-Frequency Plasmas; Cambridge University Press: Cambridge, UK, 2011 ; p. 394.

32. Gorjanc, M.; Mozetič, M.; Primc, G.; Vesel, A.; Spasić, K.; Puač, N.; Petrović, Z.L.; Kert, M. Plasma treated polyethylene terephthalate for increased embedment of UV-responsive microcapsules. Appl. Surf. Sci. 2017, 419, 224-234. [CrossRef]

33. Vesel, A.; Primc, G.; Zaplotnik, R.; Mozetič, M. Applications of highly non-equilibrium low-pressure oxygen plasma for treatment of polymers and polymer composites on an industrial scale. Plasma Phys. Control. Fusion 2020, 62, 024008. [CrossRef]

34. Primc, G.; Mozetič, M. Neutral reactive gaseous species in reactors suitable for plasma surface engineering. Surf. Coat. Technol. 2019, 376, 15-20. [CrossRef]

35. Golja, B.; Tavčer, P.F. Textile functionalisation by printing fragrant, antimicrobial and flame-retardant microcapsules. Tekstilec 2016, 59, 278-288. [CrossRef]

36. Golja, B.; Forte-Tavčer, P. Behaviour of printed melamine-formaldehyde microcapsules exposed to different mechanical impacts. In Magic World of Textiles: Book of Proceedings, Proceeding of the 5th International Textile, Clothing E Design Conference, Dubrovnik, Croatia, 3-6 October 2010; Dragčević, Z., Ed.; University of Zagreb: Zagreb, Croatia, 2010; pp. 360-364.

37. Golja, B. Funkcionalizacija Tekstilij z Nanosom Mikrokapsul. Ph.D. Thesis, University of Ljubljana, Ljubljana, Slovenia, 2013.

38. Puač, N.; Petrović, Z.L.; Živković, S.; Giba, Z.; Grubišić, D.; Đorđević, A.R. Low temperature plasma treatment of dry empress-tree seeds. In Plasma Processes and Polymers; D'Agostino, R., Favia, P., Oehr, C., Wertheimer, M.R., Eds.; Whiley: Weinheim, Germany, 2005; pp. 193-203.

39. Gorenšek, M.; Gorjanc, M.; Bukošek, V.; Kovač, J.; Petrović, Z.; Puac, N. Functionalization of polyester fabric by Ar/N2 plasma and silver. Text. Res. J. 2010, 80, 1633-1642. [CrossRef]

40. ISO 13934-1:2013 Textiles—Tensile Properties of Fabrics_Part 1: Determination of Maximum Force and Elongation at Maximum Force Using the Strip Method; International Organization for Standardization: Geneva, Switzerland, 2013.

41. Gorjanc, M.; Bukošek, V.; Gorenšek, M.; Mozetič, M. CF4 plasma and silver functionalized cotton. Text. Res. J. 2010, 80, 2204-2213. [CrossRef]

42. ASTM D 1388-18 Standard Test Method for Stiffness of Fabrics; ASTM International: West Conshohocken, PA, USA, 2018; Volume 07.01. [CrossRef]

43. Gorjanc, M.; Jazbec, K.; Maloprav, A.; Godec, M.; Forte-Tavčer, P.; Simončič, B. Creation of "lotus effect" on cotton fabric with use of plasma, enzymes and sol-gel finishing. Tekstilec 2012, 55, 206-214. 
44. DIN 53924 Testing of Textiles_Velocity of Soaking Water of Textile Fabrics (Method by Determining the Rising Height); German Institute for Standardization: Berlin, Germany, 2020.

45. ISO 9237:1995 Textiles-Determination of Permeability of Fabrics to Air; International Organization for Standardization: Geneva, Switzerland, 1995.

46. ISO 105-C06:2010 Textiles-Tests for Colour Fastness_Part C06: Colour Fastness to Domestic and Commercial Laundering; International Organization for Standardization: Geneva, Switzerland, 2010.

47. Jolliffe, I.T. Principal Component Analysis, 2nd ed.; Springer: New York, NY, USA, 2002; 487p.

48. Strlic, M.; Thomas, J.; Trafela, T.; Cséfalvayová, L.; Cigić, I.K.; Kolar, J.; Cassar, M. Material degradomics: On the smell of old books. Anal. Chem. 2009, 81, 8617-8622. [CrossRef]

49. Debeljak, M.; Hladnik, A.; Černe, L.; Gregor-Svetec, D. Use of effect pigments for quality enhancement of offset printed specialty papers. Color Res. Appl. 2013, 38, 168-176. [CrossRef]

50. Mihailović, D.; Saponjic, Z.; Radoicic, M.; Lazovic, S.; Baily, C.J.; Jovančić, P.; Nedeljkovic, J.; Radetić, M. Functionalization of cotton fabrics with corona/air RF plasma and colloidal $\mathrm{TiO}_{2}$ nanoparticles. Cellulose 2011, 18, 811-825. [CrossRef]

51. Flynn, C.; Byrne, C.; Meenan, B. Surface modification of cellulose via atmospheric pressure plasma processing in air and ammonia-nitrogen gas. Surf. Coat. Technol. 2013, 233, 108-118. [CrossRef]

52. Vesel, A.; Junkar, I.; Cvelbar, U.; Kovac, J.; Mozetic, M. Surface modification of polyester by oxygen- and nitrogen-plasma treatment. Surf. Interface Anal. 2008, 40, 1444-1453. [CrossRef]

53. Pransilp, P.; Pruettiphap, M.; Bhanthumnavin, W.; Paosawatyanyong, B.; Kiatkamjornwong, S. Surface modification of cotton fabrics by gas plasmas for color strength and adhesion by inkjet ink printing. Appl. Surf. Sci. 2016, 364, 208-220. [CrossRef]

54. Vallon, S.; Hofrichter, A.; Drévillon, B.; Klemberg-Sapieha, J.; Martinu, L.; Poncin-Epaillard, F. Improvement of the adhesion of silica layers to polypropylene induced by nitrogen plasma treatment. Thin Solid Film. 1996, 290-291, 68-73. [CrossRef]

55. Ogawa, T.; Uematsu, S.; Gejyo, M. Surface composition and its stability of nitrogen corona treated polypropylene. Kobunshi Ronbunshu 2008, 65, 67-72. [CrossRef]

56. Shahidi, S.; Ghoranneviss, M. Comparison between oxygen and nitrogen plasma treatment on adhesion properties and antibacterial activity of metal coated polypropylene fabrics. Fibers Polym. 2012, 13, 971-978. [CrossRef]

57. Babaei, S.; Fekete, N.; Hoesli, C.A.; Girard-Lauriault, P.-L. Adhesion of human monocytes to oxygen- and nitrogen-containing plasma polymers: Effect of surface chemistry and protein adsorption. Colloids Surf. B Biointerfaces 2018, 162, 362-369. [CrossRef] [PubMed] 